\title{
CHAPTER 24 \\ Good Health in the Anthropocene Epoch: Potential for Transformative Solutions
}

\author{
Andy Haines
}

Summary Unprecedented environmental changes threaten to reverse progress on health and development unless they are addressed by decisive actions. The implementation of policies to reduce the environmental impact of human societies can reduce risks and also bring a range of near-term health benefits - for example, from lowered emissions of pollutants co-emitted with greenhouse gases. This chapter outlines potential transformative policies in sectors such as energy, transport, urban development and food systems, which can reduce their environmental footprint and improve health.

\section{Introduction}

Humanity faces multiple environmental challenges dominated by climate change but also encompassing ocean acidification, air pollution, biodiversity loss, declining fisheries, deforestation and depletion of freshwater supplies, which together characterise the Anthropocene epoch. The Anthropocene reflects the dominance of one species, our own, over the Earth's natural systems and is leading to rapid changes in these systems with potentially far-reaching implications for human health and development. Humanity flourished in the Holocene epoch, a relatively stable climatic period of about 11,500 years, and there is concern that the dramatic gains in life expectancy over recent decades could be undermined by these multiple environmental stressors acting in concert. Although this chapter largely addresses the challenge of climate change, it does so within the broader context of "planetary health", which acknowledges that the health of human civilisation depends on the state of underpinning natural systems (Whitmee et al., 2015).

Transformative approaches imply that health and development must increasingly be achieved at much lower environmental impacts than the current fossil fuel-intensive and inequitable world economy.

\footnotetext{
A. Haines $(\bowtie)$

London School of Hygiene and Tropical Medicine, London, UK

e-mail: andy.haines@1shtm.ac.uk
} 


\section{The Imperative of Transformative Change}

In order to attain the aims of the Paris Agreement, it will be necessary to decarbonise the world economy and implement deep cuts in short-lived climate pollutants (SLCPs) as a matter of urgency. In the absence of deep cuts in both $\mathrm{CO}_{2}$ and SLCP emissions, temperature increases are likely to exceed $1.5^{\circ} \mathrm{C}$ during the $2030 \mathrm{~s}$ and exceed $2{ }^{\circ} \mathrm{C}$ by mid-century (Ramanathan \& Xu, 2010; Shindell et al., 2012). After 3 years of stable greenhouse gas (GHG) emissions, in 2017 global GHG emissions from energy and industry increased (UNEP Emissions Gap Report, 2018).

The perception that transformative change towards a clean economy based on non-polluting renewable sources of energy is prohibitively expensive and politically unachievable in the near term is a major barrier to progress. An alternative view is that it is both inevitable and welcome because it brings many benefits in the near term as well as creating the opportunity to promote a sustainable and productive economy for the future. Health co-benefits of the "zero-carbon" economy can arise from a range of policies in sectors such as transport, energy, housing, and food and agriculture, and through several pathways, including reduced air pollution exposure, healthy low-environmental-impact diets and increased physical activity (Haines et al., 2009). These policies must be complemented by others that halt and reverse the profound damage to a range of natural systems whilst safeguarding health and development (Whitmee et al., 2015).

\section{Health Co-benefits of Reduced Air Pollution from Clean Renewable Energy Sources}

A growing body of evidence attests to the major health co-benefits that accompany policies to reduce GHG/SLCP emissions. A major pathway is through the reduction in exposure to fine particulate air pollution from a combination of ambient and household air pollution, and from tropospheric ozone. The sources of ambient air pollution vary by country, as shown in Fig. 24.1, which compares the USA and India. Ambient air pollution has been estimated to cause over 4.5 million premature deaths annually worldwide (Lelieveld, Haines, \& Pozzer, 2018).

The Global Burden of Disease (GBD) study estimated that 2.9 million deaths in 2015 were associated with household air pollution (Forouzanfar, Alexander, Anderson, et al., 2015), whereas the World Health Organization (WHO) estimated that there were 4.3 million related deaths in 2012 (WHO, 2014). This difference is partly due to the approaches used to quantify exposure-outcome associations (see Landrigan et al., 2018, for further discussion of differences between the GBD and WHO approaches). The magnitude of these health effects shows the potential improvements from universal access to clean renewable energy sources, which can be further augmented by indirect health benefits-for example, from reduced time collecting firewood for domestic use (a task that falls disproportionately on women and girls, exposing them to risks of sexual violence). 

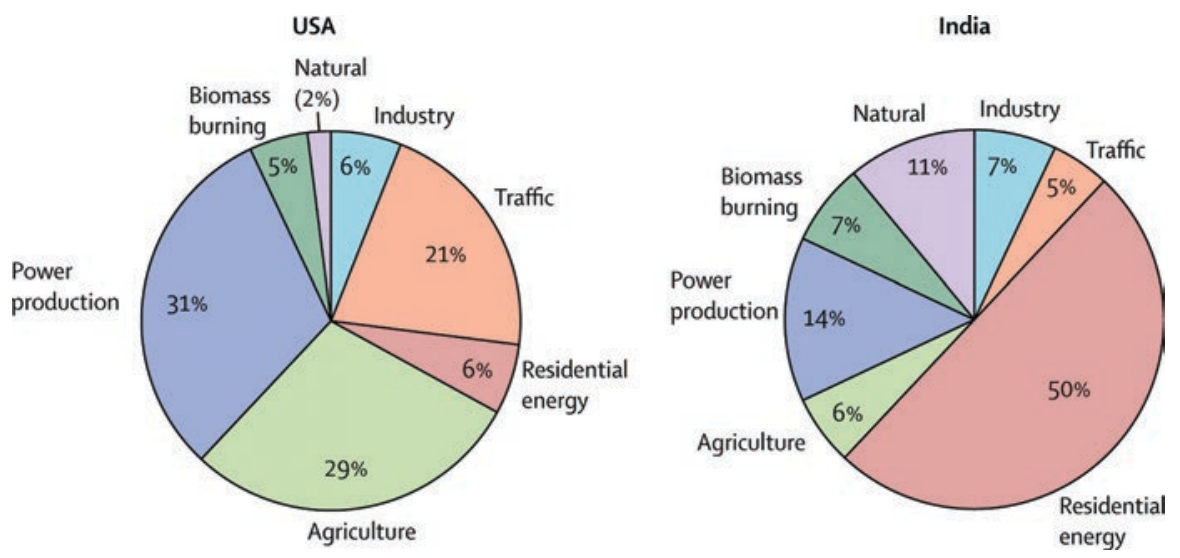

Fig. 24.1 Sources of mortality from air pollution. The percentages are the proportions of deaths attributable to ambient air pollution. Excess deaths attributable to air pollution in 2015 were estimated at 120,000 (95\% confidence interval 81,000-156,000) in the USA and 967,000 $(753,000$ $1,150,000)$ in India. "Natural" refers to natural sources of air pollution, predominantly aeolian dust. (Source: Lelieveld et al., 2018, with permission from The Lancet Planetary Health)

A growing number of studies have estimated the health co-benefits of policies to scale up access to clean energy from low-carbon and renewable sources. The International Energy Agency estimated that a 7\% increase in total energy investment over the period to 2040 in a clean air scenario would lead to a dramatic improvement in health in comparison with a main reference scenario. Premature deaths from outdoor air pollution would be 1.7 million lower in 2040, and those from household pollution would be 1.6 million lower. Furthermore, there would be additional benefits in terms of energy security, $\mathrm{CO}_{2}$ emissions and import bills (IEA, 2016).

Co-benefits may be particularly large in countries with a large burden of disease from air pollution; for example, the implementation of climate mitigation strategies in China could result in about a 50\% reduction in months of life lost as a result of air pollution exposure by 2050 (Markandya et al., 2009).

Implementing a range of SLCP mitigation actions could result in between 700,000 and 4.7 million annually avoided premature deaths, mainly from reductions in black carbon, together with increases in annual crop yields of 30-135 million metric tons due to ozone reductions in 2030 and beyond (Shindell et al., 2012). The measures to reduce black carbon emissions include reduced agricultural burning, replacement of domestic solid fuels with clean sources of energy and use of improved-efficiency brick kilns. Methane reductions could be achieved by reducing leakage of natural gas, improved rice paddy management and so on. A rapid phaseout of fossil fuels to reduce CO emissions, together with policies to cut SLCPs, offer the best prospect of achieving the targets in the Paris Agreement and will provide both near- and long-term benefits to health (Shindell et al., 2017).

There are a number of potential approaches to reducing exposure to household air pollution, including improved-efficiency cookstoves, electrification (preferably 
from low-carbon sources) and use of liquefied petroleum gas (LPG). LPG is a fossil fuel and therefore would result in a small increase in $\mathrm{CO}_{2}$ emissions but much lower particulate air pollution exposure (Pachauri, 2014).

Careful evaluation of effects is necessary because the anticipated benefits are not inevitable. A large-scale trial evaluating the effects of use of a cleaner-burning biomass-fuelled cookstove and solar panel versus continuation of open-fire cooking on pneumonia in children living in two rural districts of Malawi showed no effect on childhood pneumonia, probably because of low usage of the stoves, the failure of the stoves to reduce air pollution emissions sufficiently and the persistence of other sources of local air pollution (Mortimer et al., 2017). Integrated solutions are needed that address all major local sources of fine particulate air pollution, using affordable, culturally acceptable technologies that can be easily repaired and maintained. Access to electricity generated from clean renewable sources or stoves that use clean renewable fuels such as ethanol and biogas can bring large climate change and SLCP benefits (WHO/CCAC, 2016). The replacement of kerosene lamps with solar lamps reduces emissions of black carbon, resulting in benefits to the climate and to health, as well as reducing poor households' expenditure on kerosene (Climate and Clean Air Coalition, 2014).

\section{Valuation of the Air Pollution Co-benefits of Mitigation Strategies}

A study comparing a reference scenario with a global GHG mitigation scenario projected that the latter would avoid $0.5 \pm 0.2$ million and $1.3 \pm 0.5$ million premature deaths in 2030 and 2050, respectively. The global average marginal co-benefits of avoided mortality were estimated to be valued at US\$50-380 per metric ton of $\mathrm{CO}_{2}$ (using the value of a statistical life), which would exceed marginal abatement costs in 2030 and 2050 (West et al., 2013) and would tend to be largest in locations where the current air pollution health burdens are greatest. A comparison of a climate change mitigation policy scenario that is consistent with the European Commission's $2^{\circ}$ target and a baseline medium-high emissions scenario showed major health and economic co-benefits (Holland et al., 2011).

The monetised human health benefits associated with air quality improvements from reduced ozone and fine particulate pollution resulting from GHG mitigation policies could offset $26-1050 \%$ of the cost of US carbon policies. Larger net cobenefits could result from policies that minimised costs, such as cap-and-trade standards, than from specific sectoral policies (electricity and transportation) (Thompson, Rausch, Saari, \& Selin, 2014). An assessment of fine particulate and ozone reductions from a US emissions trajectory consistent with $2{ }^{\circ} \mathrm{C}$ warming from energy and vehicles showed that by 2030 , clean energy policies could prevent about 175,000 premature deaths, with 22,000 (95\% confidence interval 11,000-96,000) fewer annually thereafter (Shindell, Lee, \& Faluvegi, 2016). Furthermore, clean transpor- 
tation could prevent $\sim 120,000$ premature air pollution-related deaths by 2030 and subsequently 14,000 (9000-52,000) annually.

A retrospective analysis of the effects of implementation of US state-level renewable energy (RE) portfolio standards in 2013 showed that in addition to reductions in life cycle GHG emissions estimated at 59 million metric tons of carbon dioxide-equivalent $\left(\mathrm{CO}_{2} \mathrm{e}\right)$, there were substantial air pollution, health and environmental benefits (Wiser et al., 2016).

\section{Cities}

Most of the world's population now lives in cities, and an additional 2.5 billion people are projected to live in cities by 2050, largely in sub-Saharan Africa and in Asia (United Nations Environment Programme, 2013). Cities provide multiple and interconnected routes for realising environmental and health benefits. These include lower GHG emissions and air pollution, and non-communicable disease (NCD) reduction through improvement of the urban and built environment, including modifications to housing, transport and energy systems (Milner, Davies, \& Wilkinson, 2012; Wilkinson \& Haines, 2015).

A large prospective study in Ontario, Canada (Creatore et al., 2016), showed that greater neighbourhood walkability was associated with a decreased prevalence of overweight and obesity and a decreased incidence of diabetes between 2001 and 2012. A large-scale cross-sectional study (Flint \& Cummins, 2016) and a nationally representative longitudinal study in the UK (Martin, Panter, Suhrcke, \& Ogilvie, 2015) both demonstrated health benefits of active travel, including a reduced risk of overweight and obesity.

The modelled effects of low-emission vehicles and increased active travel in London and Delhi showed major benefits to health, which outweighed the increased risk of exposure to road injuries (Woodcock et al., 2009). In the case of London, the main health benefits were projected to result from increased active travel, although the GHG benefits resulted largely from the introduction of low-emission vehicles.

In cities with high air pollution levels, such as Delhi, a larger proportion of the health benefits is likely to be due to air pollution reduction. However, even where concentrations of particulates with a diameter of $2.5 \mu \mathrm{m}\left(\mathrm{PM}_{2.5}\right.$ concentrations) reach $100 \mu \mathrm{g} / \mathrm{m}^{3}$, harms from increased inhalation of air pollution would exceed the benefits only if individuals exceeded $1 \mathrm{~h} 30 \mathrm{~min}$ of cycling per day or more than $10 \mathrm{~h}$ of walking per day in comparison with staying at home. In comparison with driving, the benefits of physical activity would exceed harms from air pollution at up to $3 \mathrm{~h} 30 \mathrm{~min}$ of cycling per day (Tainio et al., 2016). There could be substantial benefits to national health services; for example, if urban populations in England and Wales had patterns of walking and cycling similar to those achieved in Copenhagen, about $£ 17$ billion of costs to the National Health Service (NHS) could be averted over 20 years, increasing beyond that period because of the lag between increased physical activity and disease prevention (Jarrett et al., 2012). 
The introduction of very-low-emission vehicles (e.g. electric or electric hybrid vehicles) would result in increased health benefits from reductions in air pollution. Autonomous vehicles would bring the added benefit of reduced accidents. Electric bicycles may increase the range of travel and encourage older, unfit or physically disabled people to take up cycling (Johnson \& Rose, 2015).

Provision of accessible and secure green space may provide a number of benefits to health and the environment, including improved mental health (Bowler, BuyungAli, Knight, \& Pullin, 2010); reduced risks of fatal and non-fatal cardiovascular disease, obesity and diabetes; and improved pregnancy outcomes (WHO, 2016). The mechanisms may include reduced psychological stress; increased physical activity; and reduced air pollution, noise and heat exposure. Urban sprawl and less mixed land use (which poses a higher risk) are consistently associated with obesity in North American studies, but elsewhere the associations are more heterogeneous (Mackenbach et al., 2014). In the UK, a study of over 400,000 people showed that below 1800 housing units per square kilometre higher residential density was associated with higher adiposity, whereas above 1800 units per square kilometre, residential density was associated with significantly lower body mass index and waist circumference values and with decreased odds of obesity (Sarkar, Webster, \& Gallacher, 2017). Areas of high residential density may promote greater physical activity because of the proximity of shops and other facilities, and perhaps because they provide greater social support and community engagement. Urban sprawl may also be associated with increased risks of urban heat exposure (Stone, Hess, \& Frumkin, 2010) and with higher transport GHG emissions. A study of US cities found that doubling population-weighted density was associated with a $48 \%$ reduction in $\mathrm{CO}_{2}$ emissions from household travel and a $35 \%$ reduction in $\mathrm{CO}_{2}$ emissions from residential energy use (Lee \& Lee, 2014).

\section{Health in the Circular Economy}

There is growing interest in transforming the economy from the current, inefficient, resource-intensive, polluting approach to one based on recycling, reuse and remanufacturing, encouraging the use of renewable and biodegradable resources. Such approaches can greatly reduce exposure to hazardous waste and inefficient use of resources, ensuring that human progress is achieved at much lower levels of environmental damage than today's wasteful and inequitable economy. One example would be the introduction of policies to reduce food waste; currently about $30 \%$ of agricultural land is used to grow food that is never eaten but contributes to climate and other environmental changes. Another priority is to reduce exposure of mainly poor populations to hazardous waste dumps (Landrigan et al., 2018). The circular economy-if designed to address health, development and environmental sustainability in an integrated fashion-could both address pollution and help mitigate climate change whilst promoting decent work and livelihoods. 
A recent paper, using data from 637 Chinese cities, demonstrated the potential to combine the circular economy and climate change mitigation by capitalising on urban-industrial symbiosis, including the use of waste heat from industry in the commercial and residential sectors (Ramaswami et al., 2017). Industrial cities have high direct $\mathrm{CO}_{2}$ emissions intensity and are hot spots for interventions to reduce emissions and capitalise on the potential symbiosis.

\section{Food and Agriculture}

There are a range of potential solutions to the threats posed by environmental change to crop yields, food security and nutrition, including reduction of food waste, biofortification of crops, sustainable intensification of agriculture, sustainable aquaculture, more efficient use of water and fertiliser, and promotion of lowenvironmental-impact, healthy diets (Whitmee et al., 2015). A systematic review has shown the potential to reduce GHG emissions, together with land and water use, from shifting current intakes to environmentally more sustainable diets, suggesting that median reductions of $20-30 \%$ across these indicators are possible in highincome settings (Aleksandrowicz, Green, Joy, Smith, \& Haines, 2016). The percalorie environmental impacts were largest with consumption of ruminant meat, followed by other animal products, and smallest with consumption of plant-based foods (Green et al., 2015). Dietary shifts also resulted in modest estimated reductions in the all-cause mortality risk (Milner et al., 2017). More evidence from lowincome settings is needed.

A study using data from 555 life cycle analyses on 82 types of crops and animals showed that in comparison with the global-average income-dependent diet projected for 2050, three comparator diets-Mediterranean, pescatarian and vegetarian-resulted in 30\%, 45\% and 55\% reductions in per capita GHG emissions, respectively (Tilman \& Clark, 2014), and required much less cropland than the income-dependent diet. Compared with conventional omnivorous diets, the three alternative diets were estimated to reduce incidence rates of type 2 diabetes by $16-41 \%$ and ischaemic heart disease by $20-26 \%$. Sustainable aquaculture needs scaling up to meet increased fish requirements, as much current aquaculture depends on inputs of antibiotics, pesticides and food from unsustainable sources such as krill.

\section{Pricing Greenhouse Gas Emissions to Reduce Climate Change and Improve Health}

Removing fossil fuel subsidies and implementing carbon taxes could, if properly designed, improve health, reduce GHG emissions, redistribute wealth and stimulate employment (Cuevas \& Haines, 2015), but recent disturbances in France show the 
adverse effects of policies that increase inequalities. Estimated nationally efficient carbon prices based on self-interest (i.e. including consideration of the resulting domestic co-benefits) in 2010 prices averaged around US $\$ 57$ per ton for the top 20 emitting nations (Parry, Heine, Lis, \& Li, 2014), but there are wide differences between countries, depending on their mix of energy sources. Implementing taxation that reflects the costs of carbon dioxide emissions, local air pollution and additional transport-related externalities (such as congestion and accidental injury) from burning fossil fuels could yield additional revenues, equivalent to about $2.6 \%$ of global gross domestic product (GDP), while simultaneously reducing carbon dioxide emissions by $23 \%$ and pollution-related mortality by $63 \%$ (Parry et al., 2014).

By 2050, food-related GHG emissions could take up half the remaining GHG emissions to keep the world on track for $2{ }^{\circ} \mathrm{C}$ warming in the absence of decisive actions to address the food system. An analysis of the role of GHG-related food taxes showed that food-related GHG emissions would be reduced by $1.0 \mathrm{GtCO}_{2} \mathrm{e}$ (9.3\%) under full tax coverage and by $919 \mathrm{MtCO}_{2} \mathrm{e}(8.6 \%)$ in a regionally optimised tax scenario. About two thirds of the emissions reductions were due to reduced consumption of beef and one quarter were due to reduced milk consumption (Springmann, Godfray, Rayner, \& Scarborough, 2016). However, care would be needed to avoid potential negative health effects, particularly in low-income settings, by omitting food groups known to have health benefits from the tax regime or subsidising healthy low-emission food groups. The health benefits identified in this study $(100,000-500,000$ avoided deaths globally) were broadly similar to the potential health benefits of $500,000 \pm 200,000$ avoided premature deaths per year by 2030 that global climate policies could have on air pollution associated with coal-fired power generation (West et al., 2013).

\section{Potential Adverse Effects of Policies to Address Environmental Change}

Assessments of health co-benefits of policies to mitigate environmental change should specifically consider the potential for unintended adverse consequences (Haines et al., 2009). Some types of biofuels, such as corn alcohol, compete directly with important food crops and may contribute to food price increases, but others, such as sugar cane alcohol, do not compete directly. Increasing the energy efficiency of houses by better insulation and draught proofing may increase exposure to household air pollution unless it is accompanied by improved ventilation. Diesel engines have been promoted in some countries because of their reduced GHG emissions but have higher emissions of fine particulates and nitrogen oxides (NOx) (Wilkinson \& Haines, 2015). 


\section{The Post-2015 Development Agenda}

The post-2015 development agenda represents a major opportunity to improve health through the lens of sustainable development (Dora et al., 2015; Haines, Alleyne, Kickbusch, \& Dora, 2012). The Sustainable Development Goals (SDGs) of the United Nations will shape the development agenda until 2030, and a recent paper has outlined the links between interventions and policies to reduce the emissions of short-lived climate pollutants and the SDGs (Haines et al., 2017).

There are opportunities to harness some of the climate funding of US\$100 billion annually that was previously pledged to be provided by 2020 for mitigation and adaptation (http://www.greenclimate.fund/). This funding could help countries capitalise on the health co-benefits of climate change mitigation policies and reduce climate change impacts on health by preventing dangerous climate change.

SDG target 3.7 aims to "ensure universal access to sexual and reproductive health-care services, including for family planning, information and education, and the integration of reproductive health into national strategies and programmes." This, together with improved education of women (SDG goal 4), can improve pregnancy outcomes and the prospects for child survival through birth spacing. Although per capita GHG emissions in regions such as sub-Saharan Africa are currently low, these will grow if development is powered by fossil fuels, and population growth in vulnerable regions makes adaptation to climate change more difficult.

\section{Conclusion}

Whilst global environmental change poses major challenges to human health, there are opportunities to address disease prevention and environmental sustainability through integrated transformative policies. However, in order to realise this potential, unprecedented collaboration across sectors will be required in the coming decades. The economic and social drivers responsible for the challenges faced by humanity in the Anthropocene epoch must be addressed, including by removal of harmful subsidies, realignment of taxes to focus on health-damaging externalities, and reduction of inequities in health and wealth. Better health cannot be achieved and sustained without the recognition that human health ultimately depends on the integrity of natural systems.

\section{References}

Aleksandrowicz, L., Green, R., Joy, E. J. M., Smith, P., \& Haines, A. (2016). The impacts of dietary change on greenhouse gas emissions, land use, water use, and health: A systematic review. PLoS One, 11, e0165797. https://doi.org/10.1371/journal.pone.0165797 
Bowler, D. E., Buyung-Ali, L. M., Knight, T. M., \& Pullin, A. S. (2010). A systematic review of evidence for the added benefits to health of exposure to natural environments. BMC Public Health, 10, 456.

Climate and Clean Air Coalition (2014). Scientific advisory panel briefing: Kerosene lamps and SLCPs. https://ccacoalition.org/en/news/kerosene-lamps-are-important-target-reducingindoor-air-pollution-and-climate-emissions (retrieved October 1st 2019)

Creatore, M. I., Glazier, R. H., Moineddin, R., Fazli, G. S., Johns, A., et al. (2016). Association of neighborhood walkability with change in overweight, obesity, and diabetes. JAMA, 315, 2211. https://doi.org/10.1001/jama.2016.5898

Cuevas, S., \& Haines, A. (2015). The health benefits of a carbon tax. Lancet, 386, 7-9. Retrieved on February 16, 2020 from https://www.thelancet.com/journals/lancet/article/ PIIS0140-6736(15)00994-0/fulltext

Dora, C., Haines, A., Balbus, J., Fletcher, E., Adair-Rohani, H., Alabaster, G., et al. (2015). Indicators linking health and sustainability in the post-2015 development agenda. The Lancet, 385, 380-391.

Flint, E., \& Cummins, S. (2016). Active commuting and obesity in mid-life: Cross-sectional, observational evidence from UK Biobank. The Lancet Diabetes and Endocrinology, 4, 420-435.

Forouzanfar, M. H., Alexander, L., Anderson, H. R., et al. (2015). Global, regional, and national comparative risk assessment of 79 behavioural, environmental and occupational, and metabolic risks or clusters of risks in 188 countries, 1990-2013: A systematic analysis for the Global Burden of Disease Study 2013. Lancet, 386, 2287-2323.

Green, R., Milner, J., Dangour, A. D., Haines, A., Chalabi, Z., Markandya, A., et al. (2015). The potential to reduce greenhouse gas emissions in the UK through healthy and realistic dietary change. Climatic Change, 129, 253-265. https://link.springer.com/ article/10.1007\%2Fs10584-015-1329-y

Haines, A., Alleyne, G., Kickbusch, I., \& Dora, C. (2012). From the Earth Summit to Rio+20: Integration of health and sustainable development. Lancet, 379, 2189-2197.

Haines, A., Amann, M., Borgford-Parnell, N., Leonard, S., Kuylenstierna, J., \& Shindell, D. (2017). Short-lived climate pollutant mitigation and the sustainable development goals. Nature Climate Change, 7, 863-869.

Haines, A., McMichael, A. J., Smith, K. R., Roberts, I., Woodcock, J., Markandya, A., et al. (2009). Public health benefits of strategies to reduce greenhouse-gas emissions: Overview and implications for policy makers. Lancet, 374, 2104-2114.

Holland, M., Amann, M., Heyes, C., Rafaj, P., Schöpp, W., Hunt, A., et al. (2011). The reduction in air quality impacts and associated economic benefits of mitigation policy. Summary of results from the EC RTD ClimateCost Project. In P. Watkiss (Ed.), The ClimateCost Project. Final report. Volume 1: Europe. Sweden: Stockholm Environment Institute. ISBN: 978-91-86125-35-6.

International Energy Agency (2016). World Energy Outlook (WEO) special report 2016 energy and air pollution. Paris, France: International Energy Agency.

Jarrett, J., Woodcock, J., Griffiths, U. K., Chalabi, Z., Edwards, P., Roberts, I., et al. (2012). Effect of increasing active travel in urban England and Wales on National Health Service costs. Lancet, 379, 2198-2205.

Johnson, M., \& Rose, G. (2015). Extending life on the bike: Electric bike use by older Australians. Journal of Transport \& Health, 2, 276-283.

Landrigan, P. J., Fuller, R., Acosta, N. J. R., Adeyi, O., Arnold, R., et al. (2018). Lancet commission on pollution and health. Lancet, 391, 462-512. https://doi.org/10.1016/S0140-6736(17)32345-0

Lee, S., \& Lee, B. (2014). The influence of urban form on GHG emissions in the U.S. household sector. Energy Policy, 68, 534-549.

Lelieveld, J., Haines, A., \& Pozzer, A. (2018). Age-dependent health risk from ambient air pollu- 
tion: A modelling and data analysis of childhood mortality in middle and low-income countries. Lancet Planetary Health, 2, e292-e300.

Mackenbach, J., Rutter, H., Compernolle, S., Glonti, K., Oppert, J. M., et al. (2014). Obesogenic environments: A systematic review of the association between the physical environment and adult weight status, the SPOTLIGHT project. BMC Public Health, 14, 233. http://www. biomedcentral.com/1471-2458/14/233

Markandya, A., Armstrong, B. G., Hales, S., Chiabai, A., Criqui, P., Mima, S., et al. (2009). Public health benefits of strategies to reduce greenhouse-gas emissions: Low-carbon electricity generation. Lancet, 374, 2006-2015.

Martin, A., Panter, J., Suhrcke, M., \& Ogilvie, D. (2015). Impact of changes in mode of travel to work on changes in body mass index: Evidence from the British Household Panel Survey. Journal of Epidemiology and Community Health, 69, 753-761.

Milner, J., Davies, M., \& Wilkinson, P. (2012). Urban energy, carbon management (low carbon cities) and co-benefits for human health. Current Opinion in Environmental Sustainability, 4, 398-404.

Milner, J., Joy, E. J. M., Green, R., Harris, F., Aleksandrowicz, L., Agrawal, S., et al. (2017). Dangour A Projected health effects of realistic dietary changes to address freshwater constraints in India: A modelling study. Lancet Planetary Health, 1, e 26-e 32.

Mortimer, K., Ndamala, C. B., Naunje, A. W., Malava, J., Katundu, C., et al. (2017). A cleaner burning biomass-fuelled cookstove intervention to prevent pneumonia in children under 5 years old in rural Malawi (the Cooking and Pneumonia Study): A cluster randomised controlled trial. The Lancet, 389, 167-175.

Pachauri, S. (2014). Household electricity access a trivial contributor to CO2 emissions growth in India. Nature Climate Change, 4, 1073-1076.

Parry, I. W., Heine, M. D., Lis, E., \& Li, S. (2014). Getting energy prices right: From principle to practice. Washington, DC: International Monetary Fund.

Ramanathan, V., \& Xu, Y. (2010). The Copenhagen Accord for limiting global warming: Criteria, constraints, and available avenues. Proceedings of the National Academy of Sciences of the United States of America, 107, 8055-8062. https://doi.org/10.1073/pnas.1002293107

Ramaswami, A., Tong, K., Fang, A., Lal, R. M., Nagpure, A. S., et al. (2017). Change urban crosssector actions for carbon mitigation with local health co-benefits in China. Nature Climate Change, 7, 736-742. https://doi.org/10.1038/nclimate3373

Sarkar, C., Webster, C., \& Gallacher, J. (2017). Association between adiposity outcomes and residential density: A full-data, cross-sectional analysis of 419562 UK Biobank adult participants. Lancet Planet Health, 1, e277-e288.

Shindell, D., Borgford-Parnell, N., Brauer, M., Haines, A., Kuylenstierna, J. C. I., Leonard, S. A., et al. (2017). A climate policy pathway for near- and long-term benefits. Science, 356, 493-494.

Shindell, D., Kuylenstierna, J. C. I., Vignati, E., van Dingenen, R., Amann, M., Klimont, Z., et al. (2012). Simultaneously mitigating near-term climate change and improving human health and food security. Science, 335, 183-189.

Shindell, D. T., Lee, Y., \& Faluvegi, G. (2016). Climate and health impacts of US emissions reductions consistent with $2^{\circ} \mathrm{C}$. Nature Climate Change, 6, 503-507.

Springmann, M., Godfray, C. J., Rayner, M., \& Scarborough, P. (2016). Analysis and valuation of the health and climate change co-benefits of dietary change. Proceedings of the National Academy of Sciences of the United States of America, 113, 4146-4151.

Stone, B., Hess, J. J., \& Frumkin, H. (2010). Urban form and extreme heat events: Are sprawling cities more vulnerable to climate change than compact cities? Environmental Health Perspectives, 118, 1425-1428. https://doi.org/10.1289/ehp.0901879

Tainio, M., de Nazelle, A. J., Gotschi, T., Kahlmeier, S., Rojas-Rueda, D., Nieuwenhuijsen, M. J., et al. (2016). Can air pollution negate the health benefits of cycling and walking? Preventive Medicine, 87, 233-236. 
Thompson, T. M., Rausch, S., Saari, R. K., \& Selin, N. E. (2014). A systems approach to evaluating the air quality co-benefits of US carbon policies. Nature Climate Change, 4, 917-923.

Tilman, D., \& Clark, M. (2014). Global diets link environmental sustainability and human health. Nature, 515, 518-522.

UNEP Emissions Gap Report (2018). https://www.unenvironment.org/resources/emissions-gapreport-2018 (accessed October 1st 2019)

United Nations Environment Programme (2013). City-level decoupling: Urban resource flows and the governance of infrastructure transitions. A Report of the Working Group on Cities of the International Resource Panel. Swilling M., Robinson B., Marvin S. and Hodson M. ISBN: 978-92-807-3298-6

West, J. J., Smith, S. J., Silva, R. A., Naik, V., Zhang, Y., Adelman, Z., et al. (2013). Co-benefits of mitigating global greenhouse gas emissions for future air quality and human health. Nature Climate Change, 3, 885-889.

Whitmee, S., Haines, A., Beyrer, C., Boltz, F., Capon, A. G., et al. (2015). Safeguarding human health in the Anthropocene epoch: Report of The Rockefeller Foundation-Lancet Commission on planetary health. Lancet, 386, 1973-2028.

WHO (2016). Urban green spaces and health. Copenhagen: WHO Regional Office for Europe. http://www.euro.who.int/_data/assets/pdf_file/0005/321971/Urban-green-spaces-and-healthreview-evidence.pdf?ua $=1$

WHO/CCAC (2016). Household air pollution and health. Retrieved on February 16, 2020 from http://www.who.int/sustainable-development/LR-HAP-27May2016.pdf?ua=1

Wilkinson, P., \& Haines, A. (2015). Diesel in the dock. BMJ, 351, h5415.

Wiser, R., Barbose, G., Heeter, J., Mai, T., Bird, L., Bolinger, M., et al. (2016). A retrospective analysis of the benefits and impacts of U.S. renewable portfolio standards (NREL/ TP-6A20-65005). Lawrence Berkeley National Laboratory and National Renewable Energy Laboratory. Retrieved on February 16, 2020 from http://www.nrel.gov/docs/fy16osti/65005. pdf

Woodcock, J., Edwards, P., Tonne, C., Armstrong, B. G., Ashiru, O., Banister, D., et al. (2009). Public health benefits of strategies to reduce greenhouse-gas emissions: Urban land transport. Lancet, 374, 1930-1943.

Open Access This chapter is licensed under the terms of the Creative Commons Attribution 4.0 International License (http://creativecommons.org/licenses/by/4.0/), which permits use, sharing, adaptation, distribution and reproduction in any medium or format, as long as you give appropriate credit to the original author(s) and the source, provide a link to the Creative Commons license and indicate if changes were made.

The images or other third party material in this chapter are included in the chapter's Creative Commons license, unless indicated otherwise in a credit line to the material. If material is not included in the chapter's Creative Commons license and your intended use is not permitted by statutory regulation or exceeds the permitted use, you will need to obtain permission directly from the copyright holder.

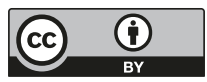

